\title{
Characterization of Biochar Properties Affected by Different Pyrolysis Temperatures Using Visible-Near-Infrared Spectroscopy
}

\author{
Haiqing Yang ${ }^{1}$ and Kuichuan Sheng ${ }^{2}$ \\ ${ }^{1}$ College of Information Engineering, Zhejiang University of Technology, Hangzhou 310032, China \\ ${ }^{2}$ School of Biosystems Engineering and Food Sciences, Zhejiang University, Hangzhou 310058, China \\ Correspondence should be addressed to Haiqing Yang, yanghq@zjut.edu.cn
}

Received 15 October 2012; Accepted 2 November 2012

Academic Editors: P. Johansson and S. Prati

Copyright (C) 2012 H. Yang and K. Sheng. This is an open access article distributed under the Creative Commons Attribution License, which permits unrestricted use, distribution, and reproduction in any medium, provided the original work is properly cited.

\begin{abstract}
Rapid characterization of biochar for energy and ecological purpose utilization is fundamental. In this work, visible and nearinfrared (vis-NIR) spectroscopy was used to measure ash, volatile matter, fixed carbon contents, and calorific value of three types of biochar produced from pine wood, cedar wood, and cotton stalk, respectively. The vis-NIR spectroscopy was also used to discriminate biochar feedstock types and pyrolysis temperature. Prediction result shows that partial least squares (PLS) regression calibrating the spectra to the values of biochar properties achieved very good or excellent performance with coefficient of determination $\left(R^{2}\right)$ of $0.86 \sim 0.91$ and residual prediction deviation (RPD) of 2.58 3.32 for ash, volatile matter, and fixed carbon, and good prediction with $R^{2}$ of 0.81 and RPD of 2.30 for calorific value. Linear discrimination analysis (LDA) of the principal components (PCs) produced from PCA of wavelength matrix shows that three types of biochar can be successfully discriminated with $95.2 \%$ accuracy. The classification of biochar with different pyrolysis temperatures can be conducted with $69 \%$ accuracy for all three types and $100 \%$ accuracy for single type of cotton stalk. This experiment suggests that the vis-NIR spectroscopy is promising as an alternative of traditionally quantitative and qualitative analysis of biochar properties.
\end{abstract}

\section{Introduction}

Biochar is the product of thermal degradation of organic materials in the absence of air (pyrolysis). Except for being an excellent material for energy purpose utilization, biochar has also been described as a possible means to improve soil fertility as well as other ecosystem services and sequester carbon $(\mathrm{C})$ to mitigate climate change $[1,2]$. Conversion of agricultural wastes into biochars not only can save natural resources but also protect environment. Biochar quality is mainly influenced by its feedstock type as well as pyrolysis conditions. However, it is very cost- and time-consuming to determinate biochar properties, for example, to measure calorific value, by using conventionally physic-chemical means in laboratory. Thus, it is necessary to develop an alternative for rapid characterization of biochar properties.

Recently, near-infrared reflectance spectroscopy (NIRS) has received increasing attention because it is characteristic of rapid measurement, ease to use, and absence of agents. This technology has been used for the analysis of biomass feedstock properties. Sanderson et al. [3] used the NIRS to determine the chemical compositions of several woody and herbaceous feedstocks, such as ethanol extractives, ash, and lignin. Labbé et al. [4] found the orthogonal signal correction- (OSC-) treated kernel PLS method achieved highest coefficient of correlation and lowest root-mean square of error (RMSE) for the prediction of ash and char content of three types of woody biomass (red oak, yellow poplar, hickory) and three herbaceous biomasses (switch grass, corn stover, sugarcane bagasse). Allison et al. [5] measured several key compositional parameters (alkali index, nitrogen, carbon, and ash contents) in two species of energy grass (switch grass and reed canary grass) by Fourier transform infrared spectroscopy. Nkansah et al. [6] used the NIRS as a process analysis technology tool for the rapid characterization of physical (bulk density) and chemical 
properties (insoluble and acid-soluble lignin, extractives, ash) of yellow-poplar. Fagan et al. [7] predicted the moisture, calorific value, ash, and carbon content of two dedicated bioenergy crops (Miscanthus and Short Rotational Coppice Willow). All reports above focused on the measurement of biomass feedstock properties. To our knowledge, however, there is no report on using the NIRS to predict biochar properties.

As known, weak overtones and combinations of the IR fundamental vibrations due to the stretching and bending of $\mathrm{N}-\mathrm{H}, \mathrm{O}-\mathrm{H}$, and $\mathrm{C}-\mathrm{H}$ groups dominate the NIR (780 $2500 \mathrm{~nm}$ ) and electronic transitions in the visible (350 $780 \mathrm{~nm}$ ) portions of the electromagnetic (EM) spectrum [8]. It might be practicable to use the visible and near-infrared (vis-NIR) spectroscopy for the characterization of biochar properties, although using IR range $\left(4000 \sim 400 \mathrm{~cm}^{-1}\right)$ may produce higher performance than vis-NIR range, as shown in other reports $[9,10]$.

This study aims to explore the potential of using vis-NIR spectrum from 350 to $1100 \mathrm{~nm}$ to determinate componential contents, that is, ash, volatile matter, and fixed-carbon contents and calorific value of three selected types of biochar produced from cedar wood, pine wood, and cotton stalk under different pyrolysis temperatures. We also investigated the feasibility of the vis-NIR spectroscopy to discriminate biochar feedstock types and pyrolysis temperatures.

\section{Material and Methods}

2.1. Sample Preparation. Pine and cedar wood chips were collected from a local timber production factory. Cotton stalk was gathered from a local farmland. The biomass wastes were left outdoors for air-drying one month. The dried materials were broken by machine and further ground to pass through a 40 mesh screen. Biochar was produced via the pyrolysis of the raw biomass at various temperatures under oxygen-limited conditions, which allowed the materials to be charred rather than combusted. Briefly, the biomass was placed in a ceramic pot covered with a fitting lid, and underwent pyrolysis in a muffle furnace with peak temperatures of $300,350,400,450,500,550$, and $600^{\circ} \mathrm{C}$ for $2 \mathrm{~h}$. For each temperature, four biochar samples were prepared for cedar and pine wood and 8 samples for cotton stalk. A total of 112 samples were used with 28,28 , and 56 samples for cedar wood, pine wood, and cotton stalk biomass, respectively.

From each sample, $4 \sim 5 \mathrm{~g}$ was used for laboratory measurement of ash, volatile matter contents (wt.\%), and calorific value $(\mathrm{MJ} / \mathrm{kg})$. The ash and volatile matter contents were measured according to the criteria of NY/T1881.4-2010 (China) and the calorific value according to the standard of GB/T 213-2003 (China). Fixed carbon content was calculated by 1 - ash (wt.\%) - volatile matter (wt.\%). All measurements were conducted on the dry base.

2.2. Spectrum Measurement. A subsample of about $5 \mathrm{~g}$ was loaded into a static ring cup and measured with a Maya 2000 spectrophotometer (Ocean Optics, USA) equipped with an optic fiber for light transmission. The light source was a halogen bulb of $3000 \mathrm{~K}$. The spectrophotometer provided spectra with wavelengths from 200 to $1150 \mathrm{~nm}$. Due to the noise at both ends, only the range from 350 to $1100 \mathrm{~nm}$ was remained for further investigation. All spectra were recorded in diffuse reflectance mode. Before sample spectral scanning, ten reference scans were taken on a ceramic standard supplied with the spectrophotometer. Twenty photometric scans were conducted and averaged for each sample.

2.3. Spectral Data Processing. The spectra were treated with the Unscrambler X10.1 (CAMO, Oslo, Norway). Spectral homogeneity of samples was tested before model calibration. A principal components analysis (PCA) of wavelength matrix was carried out for the residual $\mathrm{X}$-variance calculation on all samples. The Hotelling $T^{2}$ ellipse based on the first and second principal components (PC1 and PC2) was used to find sample outliers. No samples were found outside the Hotelling $T^{2}$ ellipse. The spectra were then randomly divided into two separate sets for calibration $(50 \%)$ and prediction $(50 \%)$.

Several spectral preprocessing algorithms, such as Savitzky-Golay smoothing, multiplicative scatter correction (MSC), standard normal variate (SNV), the 1 st and 2nd detrendings, and the 1st and 2nd derivatives, were investigated but were not useful for improving prediction performance. The only beneficial spectrum transformation was baseline offset correction (BOC), conducted by $f(\lambda)=r(\lambda)-$ $\min r(X)$, where $r(\lambda)$ is the reflectance at a wavelength of $\lambda$ and $X$ demotes all wavelength variables. The value of the lowest point in a spectrum is subtracted from all the variables. Using BOC can eliminate light-path difference caused by rough sample surface.

The BOC-transformed spectra in the calibration set were subjected to a partial least squares (PLS) regression to build a calibration model for each biochar property. All PLS models were conducted with leave-one-out cross-validation and the number of factors (NFs) used in the PLS models was determined by minimizing the predicted residual error sum of squares (PRESS). The performance of PLS models was evaluated for the prediction set.

PLS model performance was evaluated by the root mean squared error of calibration (RMSEC), cross-validation (RMSECV), and prediction (RMSEP) as follows:

$$
\text { RMSE }=\sqrt{\frac{\sum\left(X_{m}-X_{p}\right)^{2}}{N}},
$$

where $X_{m}$ is the reference value, $X_{p}$ is the PLS-predicted value, and $N$ is the number of samples used for calibration or prediction. PLS models were also evaluated by the residual predictive deviation (RPD), which is the ratio of standard deviation of reference values of the prediction set to the RMSEP. The criteria adopted for RPD classification [8] was that an RPD value below 1.5 indicates very poor model predictions and that such a value could not be useful; an RPD value between 1.5 and 2.0 indicates a possibility of distinguishing between large and small values, while a value between 2.0 and 2.5 makes approximate quantitative 
TABle 1: Average value and standard deviation of ash, volatile matter (VM), fixed carbon (Fc) contents, and calorific value (CV) of three types of raw biomass and charred materials under different pyrolysis temperatures.

\begin{tabular}{|c|c|c|c|c|c|c|c|c|c|}
\hline \multirow{2}{*}{$\begin{array}{l}\text { Feedstock } \\
\text { type }\end{array}$} & \multirow{2}{*}{$\begin{array}{l}\text { Material } \\
\text { property }\end{array}$} & \multirow{2}{*}{$\begin{array}{c}\text { Raw } \\
\text { biomass (control) }\end{array}$} & \multicolumn{7}{|c|}{ Pyrolysis temperature } \\
\hline & & & $300^{\circ} \mathrm{C}$ & $350^{\circ} \mathrm{C}$ & $400^{\circ} \mathrm{C}$ & $450^{\circ} \mathrm{C}$ & $500^{\circ} \mathrm{C}$ & $550^{\circ} \mathrm{C}$ & $600^{\circ} \mathrm{C}$ \\
\hline \multirow{4}{*}{ Cedar wood } & Ash (wt.\%) & $0.3 \pm 0.1$ & $1.5 \pm 0.3$ & $1.6 \pm 0.1$ & $1.6 \pm 0.1$ & $1.8 \pm 0.1$ & $1.8 \pm 0.1$ & $2.0 \pm 0.3$ & $2.1 \pm 0.1$ \\
\hline & VM (wt.\%) & $82.4 \pm 0.1$ & $37.5 \pm 0.7$ & $34.8 \pm 0.3$ & $32.6 \pm 0.7$ & $29.3 \pm 0.5$ & $25.8 \pm 0.6$ & $21.5 \pm 0.5$ & $18.4 \pm 0.4$ \\
\hline & Fc (wt.\%) & $17.3 \pm 0.1$ & $61.1 \pm 0.9$ & $63.7 \pm 0.3$ & $65.8 \pm 0.7$ & $69.0 \pm 0.4$ & $72.4 \pm 0.6$ & $76.5 \pm 0.4$ & $79.5 \pm 0.4$ \\
\hline & $\mathrm{CV}(\mathrm{MJ} / \mathrm{kg})$ & $20.5 \pm 0.1$ & $25.1 \pm 0.1$ & $25.8 \pm 0.1$ & $25.5 \pm 0.1$ & $27.1 \pm 0.1$ & $27.9 \pm 0.1$ & $28.9 \pm 0.1$ & $29.5 \pm 0.1$ \\
\hline \multirow{4}{*}{ Pine wood } & Ash (wt.\%) & $0.2 \pm 0.1$ & $2.5 \pm 0.1$ & $1.7 \pm 0.1$ & $2.0 \pm 0.1$ & $2.6 \pm 0.1$ & $3.1 \pm 0.1$ & $4.1 \pm 0.1$ & $4.7 \pm 0.3$ \\
\hline & VM (wt.\%) & $84.4 \pm 0.2$ & $37.3 \pm 0.4$ & $32.5 \pm 0.4$ & $30.5 \pm 0.3$ & $27.0 \pm 0.5$ & $23.1 \pm 0.2$ & $19.9 \pm 0.2$ & $17.2 \pm 0.7$ \\
\hline & Fc (wt.\%) & $15.4 \pm 0.2$ & $60.2 \pm 0.5$ & $65.8 \pm 0.5$ & $67.5 \pm 0.3$ & $70.4 \pm 0.6$ & $73.8 \pm 0.2$ & $76.0 \pm 0.2$ & $78.1 \pm 0.9$ \\
\hline & $\mathrm{CV}(\mathrm{MJ} / \mathrm{kg})$ & $19.2 \pm 0.1$ & $25.6 \pm 0.1$ & $25.9 \pm 0.1$ & $26.5 \pm 0.1$ & $27.6 \pm 0.1$ & $28.6 \pm 0.1$ & $28.7 \pm 0.1$ & $28.8 \pm 0.1$ \\
\hline \multirow{4}{*}{ Cotton stalk } & Ash (wt.\%) & $5.4 \pm 0.1$ & $6.0 \pm 0.1$ & $7.6 \pm 0.1$ & $8.3 \pm 0.2$ & $9.5 \pm 0.2$ & $9.2 \pm 0.2$ & $11.1 \pm 0.1$ & $10.1 \pm 0.1$ \\
\hline & VM (wt.\%) & $74.4 \pm 0.1$ & $32.2 \pm 0.3$ & $29.9 \pm 0.3$ & $24.6 \pm 0.3$ & $23.7 \pm 0.3$ & $20.8 \pm 0.6$ & $18.2 \pm 0.7$ & $15.6 \pm 1.2$ \\
\hline & Fc (wt.\%) & $20.2 \pm 0.1$ & $61.8 \pm 0.4$ & $62.5 \pm 0.4$ & $67.1 \pm 0.1$ & $66.9 \pm 0.1$ & $70.0 \pm 0.4$ & $70.7 \pm 0.6$ & $74.2 \pm 1.4$ \\
\hline & $\mathrm{CV}(\mathrm{MJ} / \mathrm{kg})$ & $18.8 \pm 0.1$ & $25.7 \pm 0.1$ & $25.2 \pm 0.1$ & $26.9 \pm 0.1$ & $25.3 \pm 0.1$ & $26.4 \pm 0.1$ & $26.9 \pm 0.1$ & $27.6 \pm 0.1$ \\
\hline
\end{tabular}

TABLE 2: Intercorrelation coefficients among ash, volatile matter $(\mathrm{VM})$, fixed carbon $(\mathrm{Fc})$ contents, and calorific value $(\mathrm{CV})$ of biochar samples.

\begin{tabular}{lcccc}
\hline & Ash (wt.\%) & VM (wt.\%) & Fc (wt.\%) & CV (MJ/kg) \\
\hline Ash (wt.\%) & 1 & -0.52 & 0.03 & -0.14 \\
VM (wt.\%) & -0.52 & 1 & -0.87 & -0.73 \\
Fc (wt.\%) & 0.03 & -0.87 & 1 & 0.94 \\
CV (MJ/kg) & -0.14 & -0.73 & 0.94 & 1 \\
\hline
\end{tabular}

predictions possible. For RPD values between 2.5 and 3.0 and above 3.0, the prediction is classified as good and excellent, respectively. We also evaluated the model performance by means of the coefficient of determination $\left(R^{2}\right)$ for prediction. In fact, $R^{2}$ indicates the percentage of the variance in the $Y$ variable that is accounted for by the $X$ variable [11]. An $R^{2}$ between 0.50 and 0.65 indicates that more than $50 \%$ of the variance in $Y$ is accounted for by variable $X$, so that discrimination between high and low concentrations may be made. An $R^{2}$ between 0.66 and 0.81 indicates approximate quantitative prediction, whereas an $R^{2}$ between 0.82 and 0.90 reveals good prediction. Calibration models having an $R^{2}$ above 0.91 are considered to be excellent. Generally, a good model prediction would have large values of $R^{2}$ and RPD, and small values of RMSEC, RMSECV, and RMSEP.

To find potential patterns in the vis-NIR spectra for discriminating feedstock types and pyrolysis temperatures of biochars, linear discriminant analysis (LDA) algorithm was used to investigate the first 10 principal components (PCs) obtained from the PCA. Potential clusters for different biochar types were separated with the Mahalanobis distance [12]. The PC-LDA models were developed for the calibration set and validated with the prediction set. The PC-LDA method was also used for discriminating biochar pyrolysis temperatures based on the combined spectra of all three biochar types. By comparison, an extra PC-LDA model was built for the single-type spectra of cotton stalk, as the number of cedar wood and pine wood biochar samples was not sufficient to develop an individual model for each of both types. Parsimonious PC-LDA models were determined in terms of minimal number of PCs for best prediction performance.

\section{Results and Discussion}

3.1. Characteristics of the Samples. The componential contents and calorific values of the raw biomass and charred materials were shown in Table 1. Generally, the values of each property changed with pyrolysis temperature. Taking cedar wood as an example, volatile matter (VM) contents decreased sharply from $82.4 \%$ in raw biomass to $37.5 \%$ at $300^{\circ} \mathrm{C}$ till to $18.4 \%$ at $600^{\circ} \mathrm{C}$. Fixed carbon $(\mathrm{Fc})$ content increased significantly from $17.3 \%$ in raw biomass to $61.1 \%$ at $300^{\circ} \mathrm{C}$ till to $79.5 \%$ at $600^{\circ} \mathrm{C}$. Ash content also increased with pyrolysis temperatures. Ash contents at $300^{\circ} \mathrm{C}(1.5 \%)$ and $600^{\circ} \mathrm{C}(2.1 \%)$ were 5 and 7 times greater than that in raw biomass $(0.3 \%)$. Calorific values also increased from $20.5 \mathrm{MJ} / \mathrm{kg}$ in raw biomass to $25.1 \mathrm{MJ} / \mathrm{kg}$ at $300^{\circ} \mathrm{C}$ and $29.5 \mathrm{MJ} / \mathrm{kg}$ at $600^{\circ} \mathrm{C}$. These changes of biochar properties affected by pyrolysis temperatures were consistent with other reports on woody biomass pyrolysis [13-15]. This observation indicates that biomass carbonization was accelerated with pyrolysis temperatures $[14,16]$. Generally, the primary thermal degradation of biomass occurs at a lower pyrolysis temperature. The pyrolytic volatiles were further cracked into low molecular weight organics and gases rather than biochar as the pyrolysis temperature increased [17]. Losses in hydrogen and oxygen content at high pyrolysis temperature were attributed to the cleavage and cracking of weak bonds within the biochar structure [18].

Table 2 presents the intercorrelation among ash, volatile matter, fixed carbon, and calorific value of all biochar samples. Obviously, there is a strong correlation between volatile matter and fixed carbon with correlation coefficient $(r)$ of -0.87 , which indicates that gasification of volatile matter at high temperature will lead to the increase of fixed carbon content. The correlation coefficient of 0.94 
TABLE 3: Statistics of calibration and prediction samples.

\begin{tabular}{lcccc}
\hline \multirow{2}{*}{ Biochar property $^{\mathrm{a}}$} & \multicolumn{2}{c}{ Calibration set } & \multicolumn{2}{c}{ Prediction set } \\
& Range & Mean \pm s.d. ${ }^{\mathrm{b}}$ & $1.4 \sim 11.1$ & Mean \pm s.d. \\
\hline Ash (wt.\%) & $1.4 \sim 11.2$ & $4.5 \pm 3.3$ & $14.9 \sim 38.0$ & $4.5 \pm 3.3$ \\
VM (wt.\%) & $14.6 \sim 37.5$ & $26.3 \pm 6.7$ & $59.6 \sim 79.9$ & $26.3 \pm 6.6$ \\
Fc (wt.\%) & $60.2 \sim 79.5$ & $69.2 \pm 5.7$ & $25.0 \sim 29.6$ & $69.2 \pm 5.7$ \\
CV (MJ/kg) & $25.1 \sim 29.5$ & $26.9 \pm 1.4$ & & $26.9 \pm 1.4$ \\
\hline
\end{tabular}

${ }^{\mathrm{a}} \mathrm{VM}$ : volatile matter content; Fc: fixed carbon content; $\mathrm{CV}$ : calorific value.

bs.d.: standard deviation.

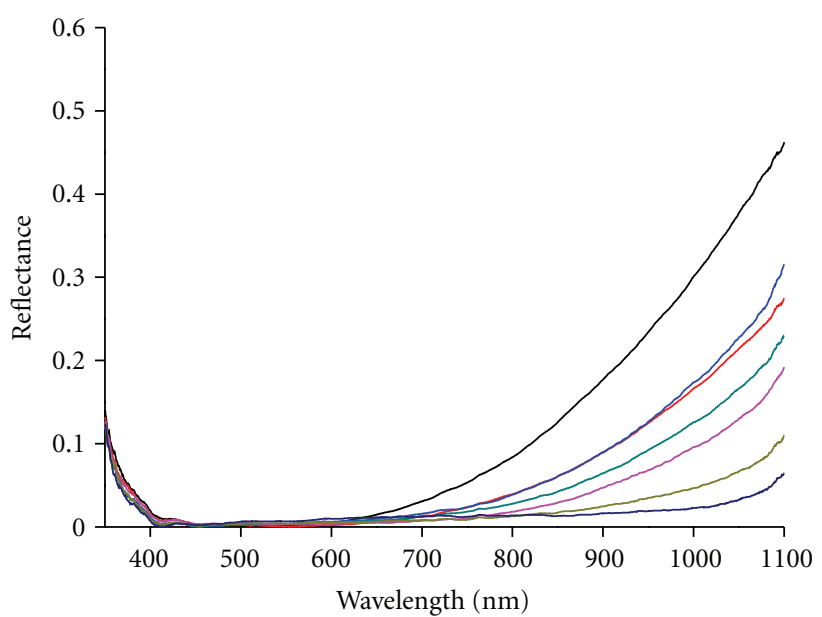

Cedar wood

$-300^{\circ} \mathrm{C}$

$-350^{\circ} \mathrm{C}$

$-400^{\circ} \mathrm{C}$

$-450^{\circ} \mathrm{C}$

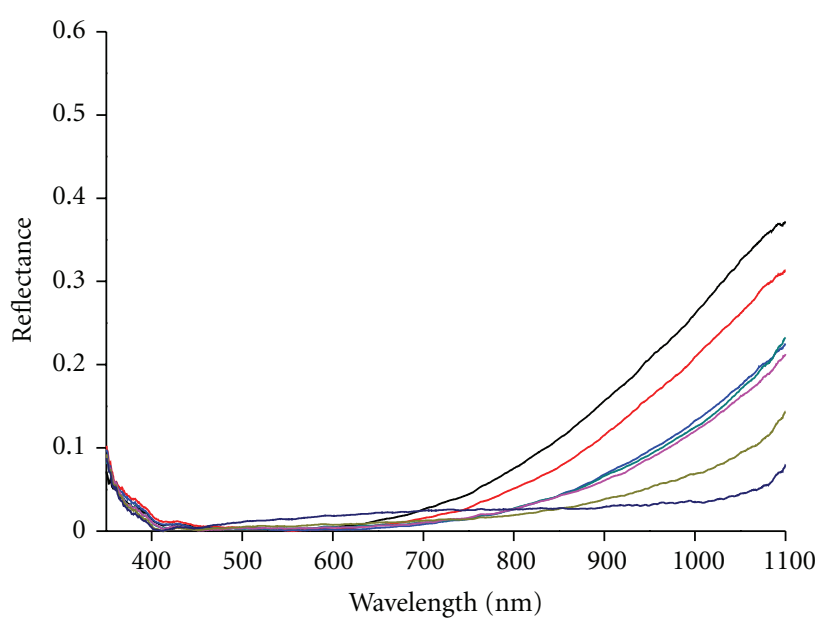

Pine wood

$-300^{\circ} \mathrm{C}$

$-350^{\circ} \mathrm{C}$

$-400^{\circ} \mathrm{C}$

$-450^{\circ} \mathrm{C}$ $-500^{\circ} \mathrm{C}$

$-550^{\circ} \mathrm{C}$

$-600^{\circ} \mathrm{C}$

(a)

(b)

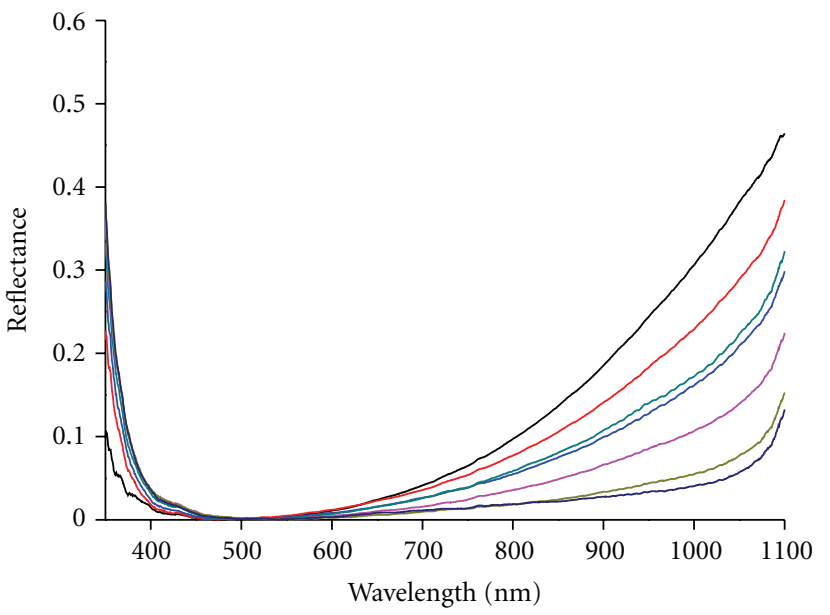

Cotton stalk

$-\quad 300^{\circ} \mathrm{C}$
$-\quad 350^{\circ} \mathrm{C}$
$-\quad 400^{\circ} \mathrm{C}$
$-\quad 450{ }^{\circ} \mathrm{C}$

$-500^{\circ} \mathrm{C}$

- $550^{\circ} \mathrm{C}$

$-600^{\circ} \mathrm{C}$

(c)

FIGURE 1: Mean BOC-transformed spectrum for the biochars produced from cedar wood (a), pine wood (b), and cotton stalk (c) affected by different pyrolysis temperatures. 
TABLE 4: Calibration and prediction results of partial least squares (PLS) regression models developed for ash, volatile matter (VM), fixed carbon $(\mathrm{Fc})$ contents and calorific value $(\mathrm{CV})$ with BOC-transformed spectra of biochar samples.

\begin{tabular}{|c|c|c|c|c|c|c|c|c|}
\hline \multirow{2}{*}{ Biochar property } & \multirow{2}{*}{$\mathrm{NFs}^{\mathrm{a}}$} & \multicolumn{4}{|c|}{ Calibration } & \multicolumn{3}{|c|}{ Prediction } \\
\hline & & $R^{2}$ & RMSEC $^{\mathrm{b}}$ & $R^{2}$ & RMSECV $^{\mathrm{c}}$ & $R^{2}$ & RMSEPd & $\mathrm{RPD}^{\mathrm{e}}$ \\
\hline Ash (wt.\%) & 8 & 0.99 & 0.3 & 0.94 & 0.8 & 0.91 & 1.0 & 3.32 \\
\hline VM (wt.\%) & 3 & 0.89 & 2.2 & 0.87 & 2.4 & 0.86 & 2.4 & 2.77 \\
\hline Fc (wt.\%) & 3 & 0.90 & 1.8 & 0.88 & 2.0 & 0.86 & 2.1 & 2.70 \\
\hline $\mathrm{CV}(\mathrm{MJ} / \mathrm{kg})$ & 3 & 0.83 & 0.56 & 0.80 & 0.63 & 0.81 & 0.60 & 2.33 \\
\hline
\end{tabular}

${ }^{a}$ Number of factors used in PLS model.

${ }^{b}$ Root mean squared error of calibration.

${ }^{\mathrm{c}}$ Root mean squared error of cross-validation.

${ }^{\mathrm{d}}$ Root mean squared error of prediction.

${ }^{\mathrm{e}}$ Residual predictive deviation, which is the ratio of standard deviation of reference values of the prediction set to the RMSEP.

between fixed carbon and calorific value may indicate the contribution of fixed carbon to biochar calorific value. Biochar properties for the calibration and prediction sets are statistically summarized in Table 3.

Figure 1 shows the changes of BOC-transformed spectra with increasing pyrolysis temperatures for each type of biochar. The spectra showed low reflectance in visible range, which corresponded to the black color of biochar. However, the reflectance became strong in the near infrared range. Pyrolysis reaction can weaken the macromolecular structure of biomass and produce biochar that is more fragile and likely to be broken [19]. Increasing pyrolysis temperature may result in a growing proportion of biochar particles with smaller size distribution [14], The changes of biochar compositions and particle sizes may contribute to the spectrum changes.

3.2. PLS Determination of Biochar Properties. The PLSR models calibrating the wavelengths to biochar properties achieved good or excellent performance for calibration and prediction (Table 4). For example, the PLS model for ash content produced $R^{2}$ of 0.94 and RMSECV of $0.8 \%$ for cross-validation, and $R^{2}$ of 0.91 , RMSEP of $1.0 \%$, and RPD of 3.32 for prediction. The PLS models for volatile matter and fixed carbon content were both developed with 3 factors and achieved similar performance with $R^{2}$ of $0.87 \sim 0.88$ and RMSECV of $2.0 \sim 2.4 \%$ for cross-validation, and $R^{2}$ of 0.86 , RMSEP of 2.1 2.4 and RPD of 2.70 2.77 for prediction. By comparison, the PLS model for biochar calorific value produced middle-level accuracy with $R^{2}$ of 0.80 and RMSECV of $0.63 \mathrm{MJ} / \mathrm{kg}$ for cross-validation, and $R^{2}$ of 0.81 , RMSEP of $0.60 \mathrm{MJ} / \mathrm{kg}$ and RPD of 2.33 for prediction.

\subsection{Discrimination of Biochar Types and Pyrolysis Temper-} atures. It is difficult to identify biochar types from their visual darkness. PCA was used to convert the wavelength matrix into a small number of PCs. Linear discrimination analysis (LDA) was then conducted for the obtained PCs to find potential patterns for discriminating different biochar types. Table 5 showed the discrimination accuracy of the PC-LDA models with various numbers of PCs in calibration and prediction. For the calibration set, these models
TABLE 5: Influence of the number of principal components (PCs) on the discrimination accuracy of biochar types using principal components-linear discriminant analysis (PC-LDA) models in calibration and prediction.

\begin{tabular}{lcc}
\hline $\begin{array}{l}\text { Number of PCs used } \\
\text { in PC-LDA models }\end{array}$ & $\begin{array}{c}\text { Discrimination accuracy of biochar types } \\
\text { Calibration }\end{array}$ & Prediction \\
\hline 6 & $100 \%$ & $90.5 \%$ \\
5 & $100 \%$ & $88.1 \%$ \\
4 & $100 \%$ & $95.2 \%$ \\
3 & $95.3 \%$ & $90.5 \%$ \\
2 & $88 \%$ & $88.1 \%$ \\
\hline
\end{tabular}

performed perfect with $100 \%$ discrimination accuracy with 4 or more PCs, $95.3 \%$ with 3 PCs, and $88 \%$ with 2 PCs. For the prediction set, however, the models reached the best performance of $95.2 \%$ accuracy when 4 PCs were involved, which indicated a LDA model for more than 4 PCs overfitting and that for less than 4 underfitting. Thus, the most parsimonious model for discriminating the targeted biochar types was the LDA for 4 PCs.

Table 6 shows the result of developing PC-LDA models to discriminate biochar pyrolysis temperatures. The performance of these models changed with the increasing number of PCs. For the combined types of biochar, the LDA for 4 PCs achieved best discrimination accuracy with $98.4 \%$ for calibration and $69.0 \%$ for prediction. For the single type of cotton stalk, although LDA for 3 PCs obtained 100\% discrimination accuracy for the calibration set, the model just produced $85.7 \%$ accuracy for the prediction set. At least 5 PCs were needed for model prediction with $100 \%$ accuracy.

Although we did not exploit the issue of how different charring temperatures make influences on the molecular structures of the three targeted types of biochar, several published reports may lend us some useful knowledge on it. For examples, Peng et al. [20] revealed by scanning electron microscopy (SEM) that with increasing temperature, biochar particles became smaller and retained less original cell structure. Also, the Fourier transform infrared spectra of biochars derived from rice straw [20], pitch pine [14], and wood [15] showed that charring temperature alters the functional group of biochar, indicating a weaker adsorption intensity 
TABLE 6: Influence of the number of principal components (PCs) on the discrimination accuracy of pyrolysis temperatures of single type of cotton stalk and combined types of biochar using principal components-linear discriminant analysis (PC-LDA) models in calibration and prediction.

\begin{tabular}{|c|c|c|c|c|}
\hline \multirow{2}{*}{ Number of PCs used in PC-LDA model } & \multicolumn{2}{|c|}{ Single type of cotton stalk } & \multicolumn{2}{|c|}{ Combined types } \\
\hline & Calibration & Prediction & Calibration & Prediction \\
\hline 6 & $100 \%$ & $100 \%$ & $100 \%$ & $45.2 \%$ \\
\hline 5 & $100 \%$ & $100 \%$ & $100 \%$ & $52.4 \%$ \\
\hline 4 & $100 \%$ & $85.7 \%$ & $98.4 \%$ & $69.0 \%$ \\
\hline 3 & $100 \%$ & $85.7 \%$ & $92.1 \%$ & $69.0 \%$ \\
\hline 2 & $95.2 \%$ & $78.6 \%$ & $90.5 \%$ & $66.7 \%$ \\
\hline
\end{tabular}

of $\mathrm{O}, \mathrm{H}$, and aliphatic $\mathrm{C}$ but stronger adsorption intensity of aromatic $\mathrm{C}$ with charring temperature. Uzun et al. [21] reported that degradation of hemicelluloses and cellulose takes place at $200 \sim 300^{\circ} \mathrm{C}$ and $300 \sim 400^{\circ} \mathrm{C}$, respectively, while lignin degradation takes place at $200 \sim 700^{\circ} \mathrm{C}$. Kim et al. [14] found that formation of highly ordered aromatic structure of biochar begins at $400^{\circ} \mathrm{C}$. As the chemical, physical, and morphological changes of biochar affected by charring temperature would result in spectral changes of molecular vibration, spectroscopic analysis should be a useful tool for biochar quality monitoring and feedstock identification, although more efforts must be extended for its practical application.

\section{Conclusions}

In the study, vis-NIR reflectance spectra with wavelengths from 350 to $1100 \mathrm{~nm}$ were calibrated to the ash, volatile matter, and fixed carbon contents and calorific values of three types of biochar produced from cedar wood, pine wood, and cotton stalk under various pyrolysis temperatures. The spectra were also used to discriminate biochar feedstock types and different pyrolysis temperatures. Conclusions can be drawn as follows.

(1) Componential contents and calorific value of biochar can be predicted successfully by PLS models developed for the vis-NIR spectra. In our case, PLS models developed for BOC-transformed spectra achieved very good or excellent prediction accuracy with $R^{2}$ of $0.86 \sim 0.91$ and RPD of $2.58 \sim 3.32$ for ash, volatile matter, and fixed carbon contents, and good prediction with $R^{2}$ of 0.81 and RPD of 2.30 for calorific value.

(2) It is feasible to discriminate biochar feedstock types based on a vis-NIR spectrum. In our case, the LDA model for the principal components (PCs) obtained from PCA of vis-NIR spectra produced excellent discrimination accuracy of $95.2 \%$ for the three targeted biochar types. The number of PCs should be optimized to avoid overfitting and underfitting of the PC-LDA model.

(3) It is possible to discriminate biochars produced under different pyrolysis temperatures by PCA of vis-NIR spectra. In our case, PC-LDA model produced $100 \%$ discrimination accuracy of cotton stalk biochars produced under $300 \sim 600^{\circ} \mathrm{C}$ at interval of $50^{\circ} \mathrm{C}$. Although the discrimination of pyrolysis temperatures for the three biochar types based on the combined spectra only produced $69 \%$ accuracy in prediction, it may suffer from the small number of biochar samples. Thus, we suggest that larger number of biochar samples should be examined if a robust model for discriminating biochar types and/or pyrolysis temperatures is to be developed.

\section{Acknowledgments}

This study was financially supported by the Zhejiang Province Natural Science Foundation (Grant no. Y1090885) and the 2012 Sci-Tech Foundation for Returned Overseas Personnel sponsored by Zhejiang Province Human Resources and Social Security Bureau.

\section{References}

[1] J. Lehmann, "A handful of carbon,” Nature, vol. 447, no. 7141, pp. 143-144, 2007.

[2] J. Lehmann, "Bio-energy in the black," Frontiers in Ecology and the Environment, vol. 5, no. 7, pp. 381-387, 2007.

[3] M. A. Sanderson, F. Agblevor, M. Collins, and D. K. Johnson, "Compositional analysis of biomass feedstocks by near infrared reflectance spectroscopy," Biomass and Bioenergy, vol. 11, no. 5, pp. 365-370, 1996.

[4] N. Labbé, S.-H. Lee, H.-W. Cho, M. K. Jeong, and N. André, "Enhanced discrimination and calibration of biomass NIR spectral data using non-linear kernel methods," Bioresource Technology, vol. 99, no. 17, pp. 8445-8452, 2008.

[5] G. G. Allison, C. Morris, E. Hodgson et al., "Measurement of key compositional parameters in two species of energy grass by Fourier transform infrared spectroscopy," Bioresource Technology, vol. 100, no. 24, pp. 6428-6433, 2009.

[6] K. Nkansah, B. Dawson-Andoh, and J. Slahor, "Rapid characterization of biomass using near infrared spectroscopy coupled with multivariate data analysis: part 1 yellow-poplar (Liriodendron tulipifera L.)," Bioresource Technology, vol. 101, no. 12, pp. 4570-4576, 2010.

[7] C. C. Fagan, C. D. Everard, and K. McDonnell, "Prediction of moisture, calorific value, ash and carbon content of two dedicated bioenergy crops using near-infrared spectroscopy," Bioresource Technology, vol. 102, no. 8, pp. 5200-5206, 2011.

[8] H. Yang, B. Kuang, and A. M. Mouazen, "Quantitative analysis of soil nitrogen and carbon at a farm scale using visible and near infrared spectroscopy coupled with wavelength 
reduction," European Journal of Soil Science, vol. 63, no. 3, pp. 410-420, 2012.

[9] H. Yang and A. M. Mouazen, "Vis/near and mid-infrared spectroscopy for predicting soil $\mathrm{N}$ and $\mathrm{C}$ at a farm scale," in Infrared Spectroscopy-Life and Biomedical Sciences, T. Theophanides, Ed., pp. 185-210, Intech Press, Rijeka, Croatia, 2012.

[10] R. A. Viscarra Rossel, D. J. J. Walvoort, A. B. McBratney, L. J. Janik, and J. O. Skjemstad, "Visible, near infrared, mid infrared or combined diffuse reflectance spectroscopy for simultaneous assessment of various soil properties," Geoderma, vol. 131, no. 1-2, pp. 59-75, 2006.

[11] H. Yang, B. Kuang, and A. M. Mouazen, "In situ determination of growing stages and harvest time of tomato (Lycopersicon esculentum) fruits using fiber-optic visible-near-infrared (VisNIR) spectroscopy," Applied Spectroscopy, vol. 65, no. 8, pp. 931-938, 2011.

[12] R. De Maesschalck, D. Jouan-Rimbaud, and D. L. Massart, "The Mahalanobis distance," Chemometrics and Intelligent Laboratory Systems, vol. 50, no. 1, pp. 1-18, 2000.

[13] M. Garcia-Perez, X. S. Wang, J. Shen et al., "Fast pyrolysis of oil mallee woody biomass: effect of temperature on the yield and quality of pyrolysis products," Industrial and Engineering Chemistry Research, vol. 47, no. 6, pp. 1846-1854, 2008.

[14] K. H. Kim, J. Y. Kim, T. S. Cho, and J. W. Choi, "Influence of pyrolysis temperature on physicochemical properties of biochar obtained from the fast pyrolysis of pitch pine (Pinus rigida)," Bioresource Technology, vol. 118, pp. 158-162, 2012.

[15] M. Keiluweit, P. S. Nico, M. Johnson, and M. Kleber, "Dynamic molecular structure of plant biomass-derived black carbon (biochar)," Environmental Science and Technology, vol. 44, no. 4, pp. 1247-1253, 2010.

[16] Y. Q. Chen, H. P. Yang, X. H. Wang, S. H. Zhang, and H. P. Chen, "Biomass-based pyrolytic polygeneration system on cotton stalk pyrolysis: influence of temperature," Bioresource Technology, vol. 107, pp. 411-418, 2012.

[17] S. T. Thangalazhy-Gopakumar, S. Adhikari, H. Ravindran et al., "Physiochemical properties of bio-oil produced at various temperatures from pine wood using an auger reactor," Bioresource Technology, vol. 101, no. 21, pp. 8389-8395, 2010.

[18] A. Demirbas, "Effects of temperature and particle size on biochar yield from pyrolysis of agricultural residues," Journal of Analytical and Applied Pyrolysis, vol. 72, no. 2, pp. 243-248, 2004.

[19] H. Abdullah and H. Wu, "Biochar as a fuel: 1. properties and grindability of biochars produced from the pyrolysis of mallee wood under slow-heating conditions," Energy \& Fuels, vol. 23, no. 8, pp. 4174-4181, 2009.

[20] X. Peng, L. L. Ye, C. H. Wang, H. Zhou, and B. Sun, "Temperature- and duration-dependent rice straw-derived biochar: characteristics and its effects on soil properties of an Ultisol in southern China," Soil and Tillage Research, vol. 112, no. 2, pp. 159-166, 2011.

[21] B. B. Uzun, A. E. Pütün, and E. Pütün, "Composition of products obtained via fast pyrolysis of olive-oil residue: effect of pyrolysis temperature," Journal of Analytical and Applied Pyrolysis, vol. 79, no. 1-2, pp. 147-153, 2007. 


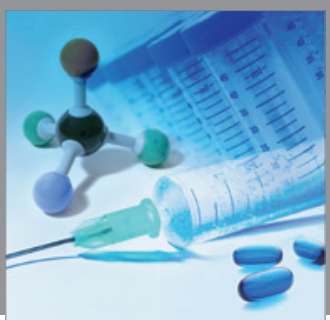

International Journal of

Medicinal Chemistry

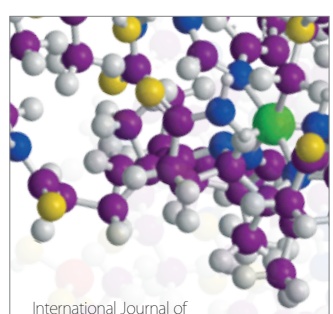

Carbohydrate Chemistry

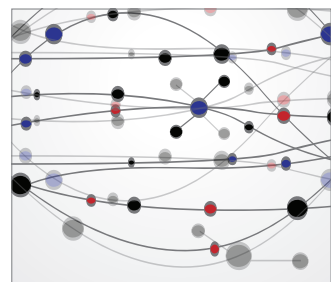

The Scientific World Journal
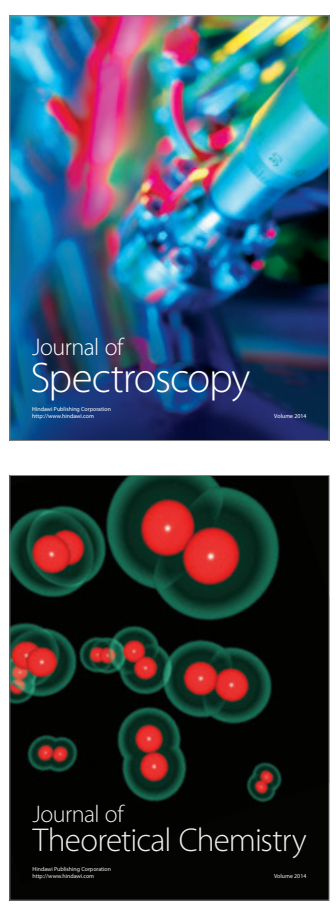
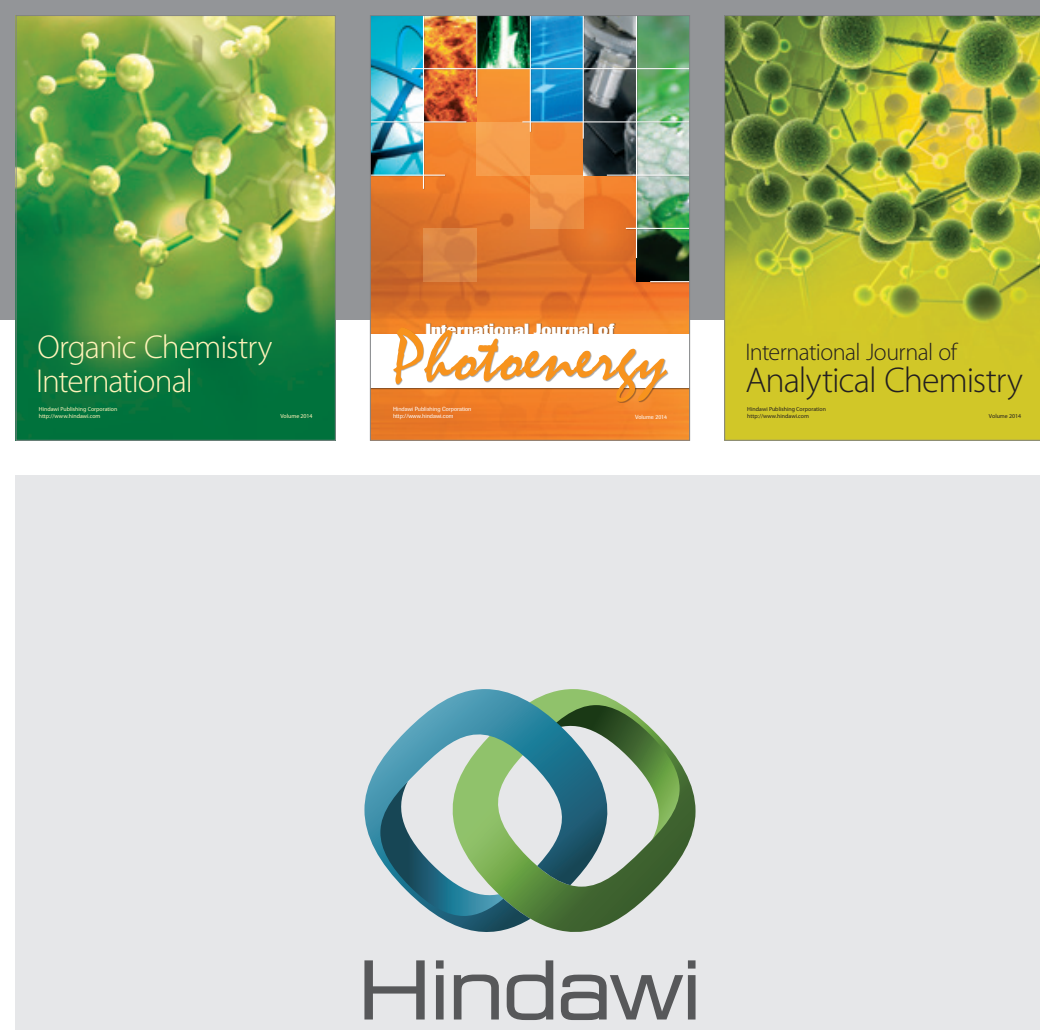

Submit your manuscripts at

http://www.hindawi.com
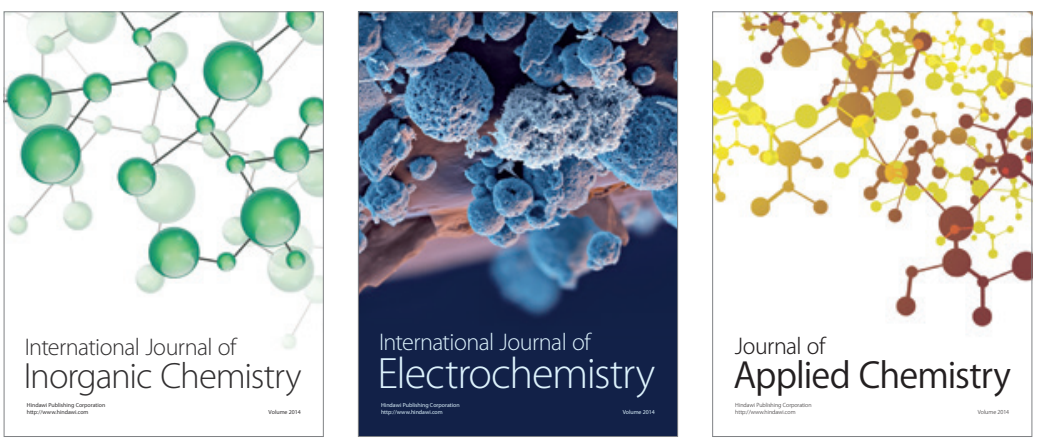

Journal of

Applied Chemistry
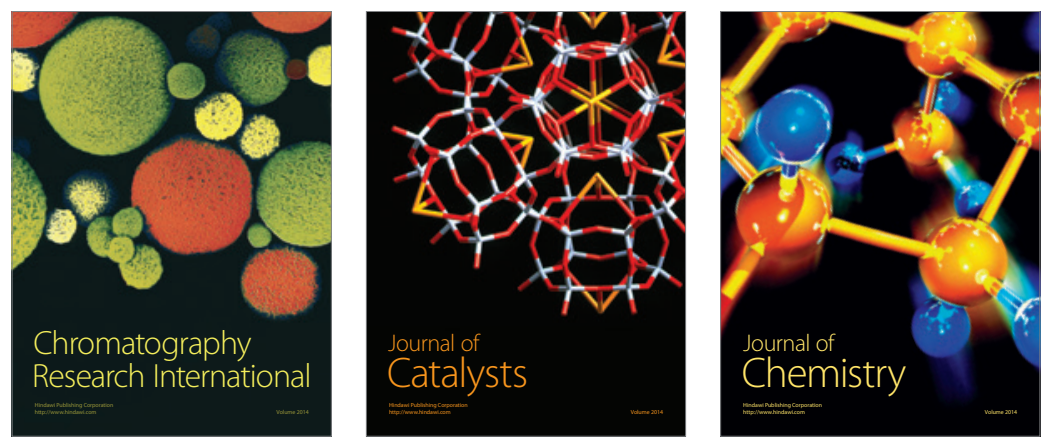
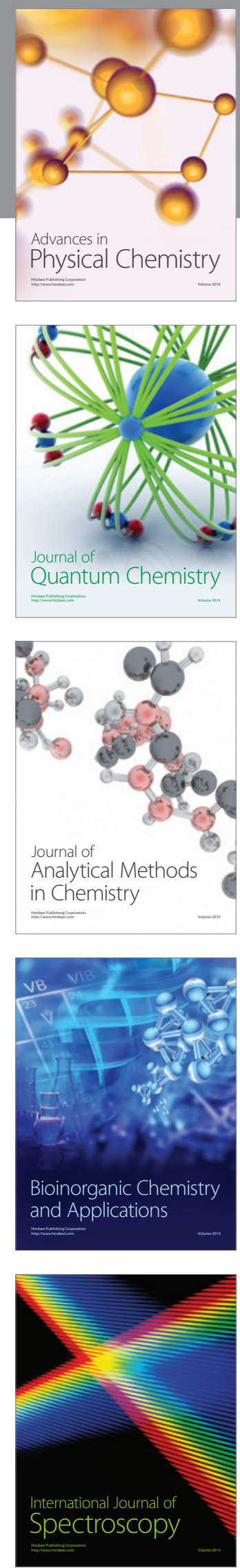